\title{
ETA PHASE FORMATION DURING THERMAL EXPOSURE AND ITS EFECT ON MECHANICAL PROPERTIES IN NI-BASE SUPERALLOY GTD 111
}

\author{
Baig Gyu Choi, In Soo Kim, Doo Hyun Kim, Seong Moon Seo and Chang Yong Jo \\ Korea Institute of Machinery \& Materials; 66 Sangnam-dong, Changwon, Kyungnam, 641-010, Korea
}

Keywords: GTD111, eta, thermal exposure, creep

\begin{abstract}
Microstructural evolutions during thermal exposure and their effects on the mechanical properties of GTD 111 have been investigated. After standard heat treatment, polycrystalline GTD 111 specimens were thermally exposed up to 10000 hours in the temperature range of $871-982^{\circ} \mathrm{C}$. Distribution and composition of the existing phases have been analyzed both quantitatively and qualitatively using electron microscopy, EDS and image analyses. The activation energy calculated for $\gamma^{\prime}$ coarsening was similar to that for self diffusion. In this alloy eta( $\eta$ ) phase may form during casting, standard heat treatment and thermal exposure at and below $927^{\circ} \mathrm{C}$. MC carbides decomposed into $\eta+\mathrm{M}_{23} \mathrm{C}_{6}$ during thermal exposure at $871{ }^{\circ} \mathrm{C}$ and $927^{\circ} \mathrm{C}$ rather than $\mathrm{M}_{23} \mathrm{C}_{6}+\gamma^{\prime}$. Precipitation of $\operatorname{sigma}(\sigma)$ phase was observed in the vicinity of $\mathrm{MC}$ or $\mathrm{M}_{23} \mathrm{C}_{6}$ carbides, especially in the specimen exposed at $871^{\circ} \mathrm{C}$. During thermal exposure at $982^{\circ} \mathrm{C}$, both precipitation of continuous $\gamma^{\prime}+\mathrm{M}_{23} \mathrm{C}_{6}$ film along the grain boundary and dissolution of fine $\eta$ within $\gamma-\gamma^{\prime}$ eutectic have occurred. Tensile tests and constant load creep tests with thermally exposed GTD 111 have been conducted to understand the effect of thermal exposure and grain boundary structure on mechanical properties. Formation of intergranular $\eta$ phase reduces the room temperature ductility, but does not affect creep rupture life and high temperature ductility in the present study.
\end{abstract}

\section{INTRODUCTION}

Ni-base superalloy GTD 111 was designed for a blade material of land-base gas turbine. It is reported that the alloy has about $20^{\circ} \mathrm{C}$ creep rupture advantage over another blade material IN738LC, as well as higher low-cycle fatigue strength ${ }^{1}$. GTD 111 is a precipitation strengthening alloy of $\gamma^{\prime}$, an intermetallic compound with the general formula of $\mathrm{Ni}_{3}(\mathrm{Al}, \mathrm{Ti})$. The alloy is known to have a multi phase microstructure consisting of $\gamma$ matrix, $\gamma^{\prime}$ precipitate, $\gamma-\gamma^{\prime}$ eutectic, carbides and some minor phases ${ }^{1}$.

The buckets in current advanced gas turbines are exposed to extremely high temperature and stress which give rise to significant microstructural degradation, such as MC carbide decomposition, agglomeration of the $\gamma^{\prime}$, and formation of minor phases. Various studies have shown that the changes of microstructure during thermal exposure or service have significant effects on the mechanical properties ${ }^{2-4}$. Therefore, the stability of microstructure of blade materials is important to the reliability of the gas turbine. In spite of important role of GTD 111 in the high temperature performance, very limited data on microstructure and mechanical properties including thermal stability of the alloy were reported $^{1,5-7}$.
It is known that the platelet $\eta$ phase exists in high-Fe wrought superalloys and as-cast condition of superalloys with high contents of $\mathrm{Ti}, \mathrm{Hf}$, or $\mathrm{Ta}^{8}$. The study reported that $\eta$ may affect mechanical properties depending on its position and morphology ${ }^{8}$. However, few data can be found on $\eta$ formation during thermal exposure and its effect on properties in cast Ni-base superalloy.

In the present study, microstructural evolutions during thermal exposure at three different temperatures up to 10000 hours and their effects on mechanical properties of the alloy have been investigated. $\eta$ phase formation during thermal exposure and its effect on mechanical properties have also been discussed.

\section{EXPERIMENTAL PROCEDURE}

The chemical composition of the GTD 111 is shown in Table 1. Master ingot (made by Cannon-Muskegon) was melted and cast into rods of $13 \mathrm{~mm}$ in diameter under vacuum. The rods were subjected to standard heat treatment $\left(1120^{\circ} \mathrm{C} / 2\right.$ hours, $843^{\circ} \mathrm{C}$ /24hours). After the standard heat treatment, the specimens were thermally exposed at $871^{\circ} \mathrm{C}, 927^{\circ} \mathrm{C}$ and $982^{\circ} \mathrm{C}$ up to 10000 hours. Microstructural observations were carried out with an optical microscope, scanning electron microscope (SEM), and transmission electron microscope (TEM). The specimens were prepared by metallographic polishing followed by etching. TEM samples were electrochemically polished with a twin jet polisher using the solution of $83 \%$ ethanol, $7 \%$ glycerol and $10 \%$ perchloric acid at $-20^{\circ} \mathrm{C} / 75 \mathrm{~V}$.

Tensile tests were carried out at room temperature and $650 \mathrm{oC}$. Constant load creep rupture tests with thermally exposed GTD 111 were conducted at $927^{\circ} \mathrm{C} / 210 \mathrm{Mpa}, 871^{\circ} \mathrm{C} / 320 \mathrm{Mpa}$, $816^{\circ} \mathrm{C} / 440 \mathrm{Mpa}$ and $760^{\circ} \mathrm{C} / 550 \mathrm{Mpa}$ on the specimens have similar grain boundary structures but different $\gamma^{\prime}$ distributions $\left(982^{\circ} \mathrm{C}\right.$, 1000 hours and $982^{\circ} \mathrm{C}, 2000$ hours), and the specimen have different minor phases distributions $\left(927^{\circ} \mathrm{C}, 2000\right.$ hours and $871^{\circ} \mathrm{C}, 10000$ hours).

Table 1. Chemical compositions of GTD 111 (wt $\%$ )

\begin{tabular}{|c|c|c|c|c|c|c|c|c|c|c|c|}
\hline $\mathrm{Ni}$ & $\mathrm{Co}$ & $\mathrm{Cr}$ & $\mathrm{Al}$ & $\mathrm{Ti}$ & $\mathrm{Ta}$ & $\mathrm{Mo}$ & $\mathrm{W}$ & $\mathrm{Zr}$ & $\mathrm{Fe}$ & $\mathrm{C}$ & $\mathrm{B}$ \\
\hline Bal. & 9.24 & 13.86 & 3.05 & 4.86 & 2.91 & 1.57 & 3.78 & 0.008 & 0.051 & 0.113 & 0.013 \\
\hline
\end{tabular}




\section{RESULTS AND DISCUSSION}

\section{ETA PHASE IN STANDARD HEAT TREATED CONDITION}

Microstructure of standard heat treated GTD 111 is shown in Figure 1. Blocky MC carbides with high contents of $\mathrm{Ti}$ and $\mathrm{Ta}$ were found mainly in interdendritic regions including grain boundaries and $\gamma-\gamma^{\prime}$ eutectic regions. The grain boundaries were covered with discontinuous $\gamma^{\prime}, \mathrm{MC}$ and very fine $\mathrm{M}_{23} \mathrm{C}_{6}$ carbides. Primary cube $\gamma^{\prime}$ and secondary fine spherical $\gamma^{\prime}$ are distributed in $\gamma$ matrix as shown in Figure 1 (b).

Figure 2 shows the different features in eautectic area in the ascast, solutionized, and standard heat treated conditions. Platelet phase with high contents of Ti and Ta was found near $\gamma-\gamma^{\prime}$ eutectic in all conditions. Figure 3, SADP(Selected Area Diffraction Pattern) of the fine plate, indicates the phase is $\eta\left(\mathrm{Ni}_{3} \mathrm{Ti}\right)$ which has the crystallographic orientation relationships with $\gamma$ matrix such as $(111)_{\gamma} / /(0001)_{\eta}$ and $[0-11]_{\gamma} / /[1-210]_{\eta}{ }^{9}$. Solutionizing increased the amount of high $\mathrm{Cr}$ content precipitates as well as fine platelet $\eta$. The width of fine platelet phase increased during aging process. The area with very fine secondary $\gamma^{\prime}$ near $\gamma-\gamma^{\prime}$ eutectic was found in standard heat treated alloy as shown in Figure 2 (c), which did not exist in as-cast condition. The $\gamma^{\prime}$ dissolution occurred during solutioniaing at $1120^{\circ} \mathrm{C}$ as shown in Figure 2 (b).
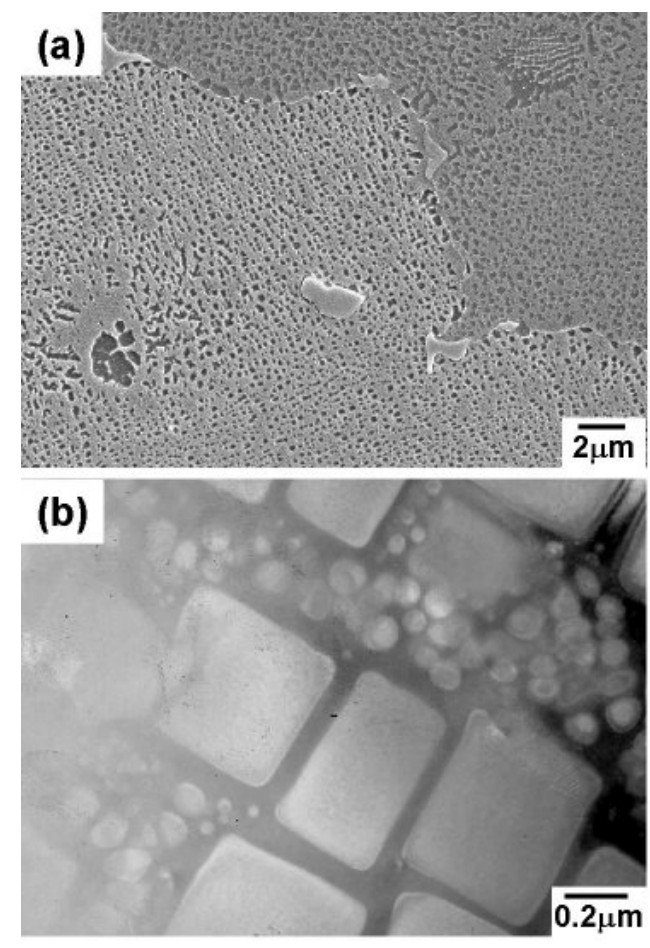

Fig. 1. Microstructure of standard heat treated GTD 111. (a) Optical micrograph, (b) TEM dark field image showing cube primary $\gamma^{\prime}$ and fine secondary $\gamma^{\prime}$.

Segregation during solidification was responsible for the evolution of microstructure near $\gamma-\gamma^{\prime}$ eutectic during heat treatment. The composition of $\gamma^{\prime}$ at each region was analyzed by energy dispersive X-ray spectrometer (EDS) in the standard heat treated specimen etched electro-chemically as shown in Table 2. $\mathrm{Co}, \mathrm{Cr}$, and $\mathrm{W}$ contents were lower and $\mathrm{Ta}$, $\mathrm{Ti}$, Ni contents were higher in $\gamma^{\prime}$ near $\gamma-\gamma^{\prime}$ eutectic region than those in dendrite core. Table 3 also shows the high contents of Ta and Ti in $\gamma-\gamma^{\prime}$ eutectic of the specimen etched by Kalling's reagent for 1 second $\left(\gamma^{\prime}\right.$ etched out slightly).
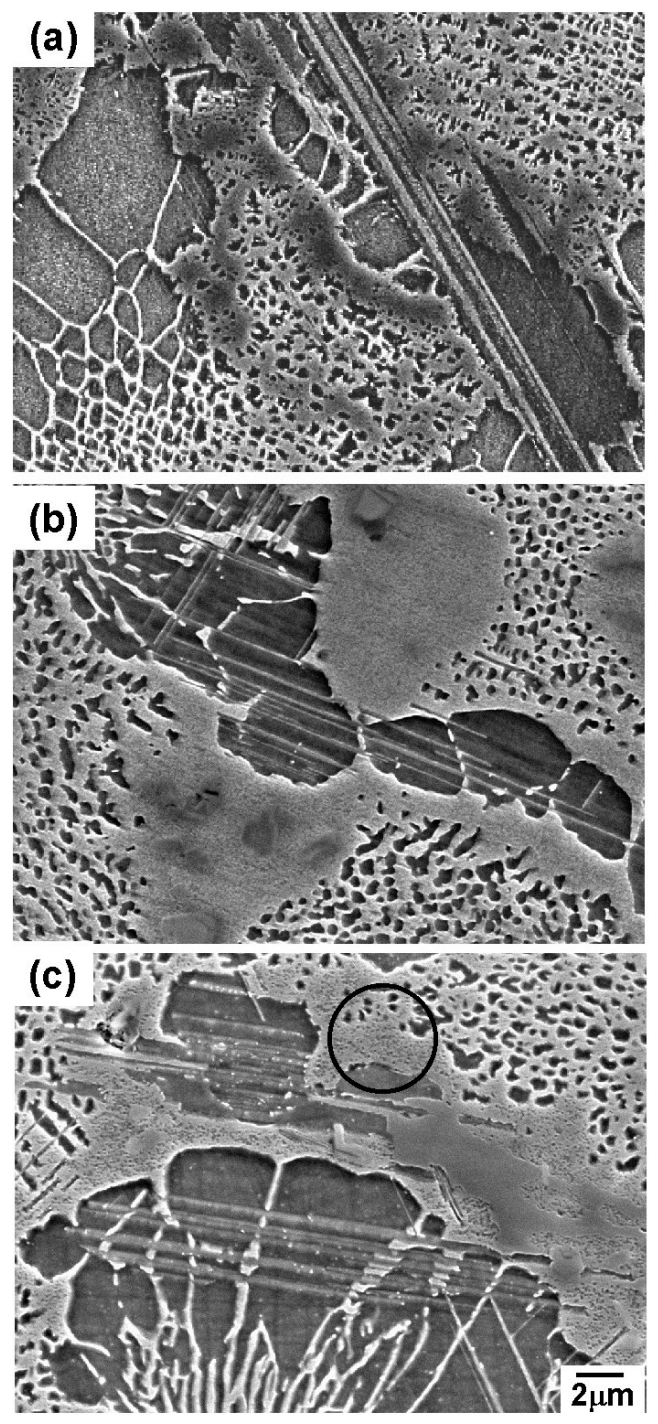

Fig. 2. SEM micrographs showing distribution of $\eta$ and fine $\gamma^{\prime}$ near $\gamma$ - $\gamma^{\prime}$ eutectic (a) as-cast, (b) after solution treatment, (c) after standard heat treatment. The circle indicates the region with fine $\gamma^{\prime}$.

Table 2. Results of EDS analysis of $\gamma^{\prime}$ for major alloying elements (in $\mathrm{wt} \%$ ) : electrolytic etching with chromic acid.

\begin{tabular}{|c|c|c|c|c|c|c|c|c|}
\hline & $\mathrm{Al}$ & $\mathrm{Ti}$ & $\mathrm{Cr}$ & $\mathrm{Co}$ & $\mathrm{Mo}$ & $\mathrm{Ta}$ & $\mathrm{W}$ & $\mathrm{Ni}$ \\
\hline $\begin{array}{c}\text { Dendrite } \\
\text { core }\end{array}$ & 2.98 & 4.61 & 9.83 & 8.52 & 0.87 & 2.57 & 3.29 & 67.43 \\
\hline $\begin{array}{c}\gamma / \gamma^{\prime} \\
\text { eutectic }\end{array}$ & 2.95 & 8.69 & 2.48 & 6.82 & - & 3.31 & 1.27 & 74.48 \\
\hline
\end{tabular}




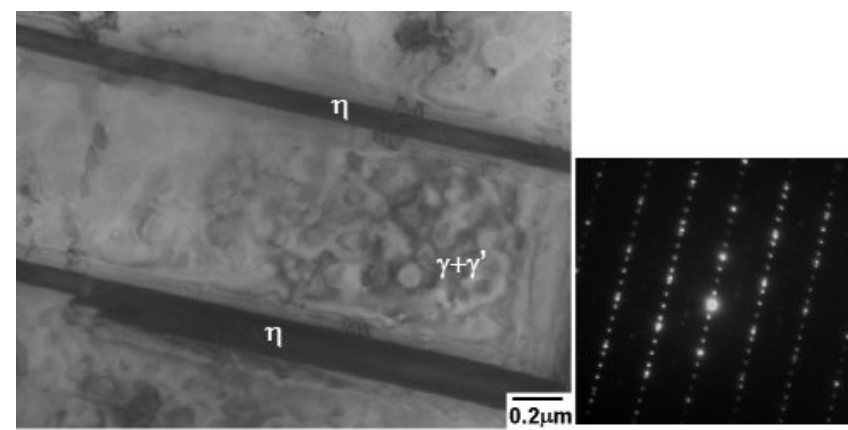

Fig. 3. TEM micrograph and selected area diffraction pattern of fine platelet phase within $\gamma-\gamma^{\prime}$ eutectic after standard heat treatment.

Tale 3. Results of EDS analysis of each region for major alloying elements (in wt\%): etched by Kalling's reagent.

\begin{tabular}{|c|c|c|c|c|c|c|c|c|}
\hline & $\mathrm{Al}$ & $\mathrm{Ti}$ & $\mathrm{Cr}$ & $\mathrm{Co}$ & $\mathrm{Mo}$ & $\mathrm{Ta}$ & $\mathrm{W}$ & $\mathrm{Ni}$ \\
\hline $\begin{array}{c}\text { Dendrite } \\
\text { core }\end{array}$ & 2.64 & 3.48 & 16.43 & 10.36 & 1.96 & 1.88 & 6.91 & 56.00 \\
\hline $\begin{array}{c}\gamma / \gamma^{\prime} \\
\text { eutectic }\end{array}$ & 2.75 & 8.59 & 9.62 & 8.57 & 1.31 & 4.41 & 3.08 & 61.68 \\
\hline
\end{tabular}

Solidification behavior of GTD111 was calculated by ThermoCalc using Scheil-Gulliver Model to see the segregation of major alloying elements. Figure 4 (a) and (b) show the composition of gamma and gamma prime respectively, as a function of solid fraction during casting. The Scheil-Gulliver equation has limitations because of its assumption that little or no back diffusion occurs in the solid phase during solidification, but the equation is adopted to predict segregation in superalloys ${ }^{10}$. As shown in Figure 4 (a) and (b), Ta and Ti contents in $\gamma$ and $\gamma^{\prime}$ are relatively low in the initial stage of solidification and high in final stage of solidification. The contents of $\mathrm{Co}$ and $\mathrm{W}$ are relatively low in $\gamma-\gamma^{\prime}$ eutectic and high in dendrite core. The calculated values show similar trend to the EDS analysis as shown in Table 2 and 3 except $\mathrm{Cr}$ content. Cr content of $\gamma^{\prime}$ in $\gamma-\gamma^{\prime}$ eutectic is a little bit higher than that in dendrite core according to Figure 4. But Table 2 shows opposite result. The difference may due to precipitation $\mathrm{Cr}$ rich carbide during solution treatment as shown in Figure 2 (b). The calculation of solidification behavior reflects the fact that the $\gamma$ phase grows as a dendrite from the liquid with a relatively high solubility for $\mathrm{Co}$ and $\mathrm{W}$ and a low solubility for Ta and $\mathrm{Ti}^{11}$.

From the above results, it can be depicted that rapid dissolution of $\gamma^{\prime}$ with high contents of Ti and Ta near the $\gamma-\gamma^{\prime}$ eutectic and segregation of the elements caused the precipitation of very fine $\gamma^{\prime}$ (Figure 2(c)), and also made it possible to precipitate the fine platelet $\eta$ phase during solutionizing.

\section{MICROSTRUCTURAL EVOLUTIONS DURING THERMAL EXPOSURE}

\section{$\underline{\text { Gamma Prime }\left(\gamma^{\prime}\right)}$}

After standard heat treatment, the primary cube $\gamma^{\prime}$ and the secondary fine spherical $\gamma^{\prime}$ are distributed in $\gamma$ matrix. The variations of intragranular $\gamma^{\prime}$ during thermal exposure at three different temperatures are shown in Figure 5. While fine $\gamma^{\prime}$ dissolved, the primary $\gamma^{\prime}$ coarsened and developed from cube to spherical shape during thermal exposure. Coarsening rate and morphological change of $\gamma^{\prime}$ were fast at high temperature.
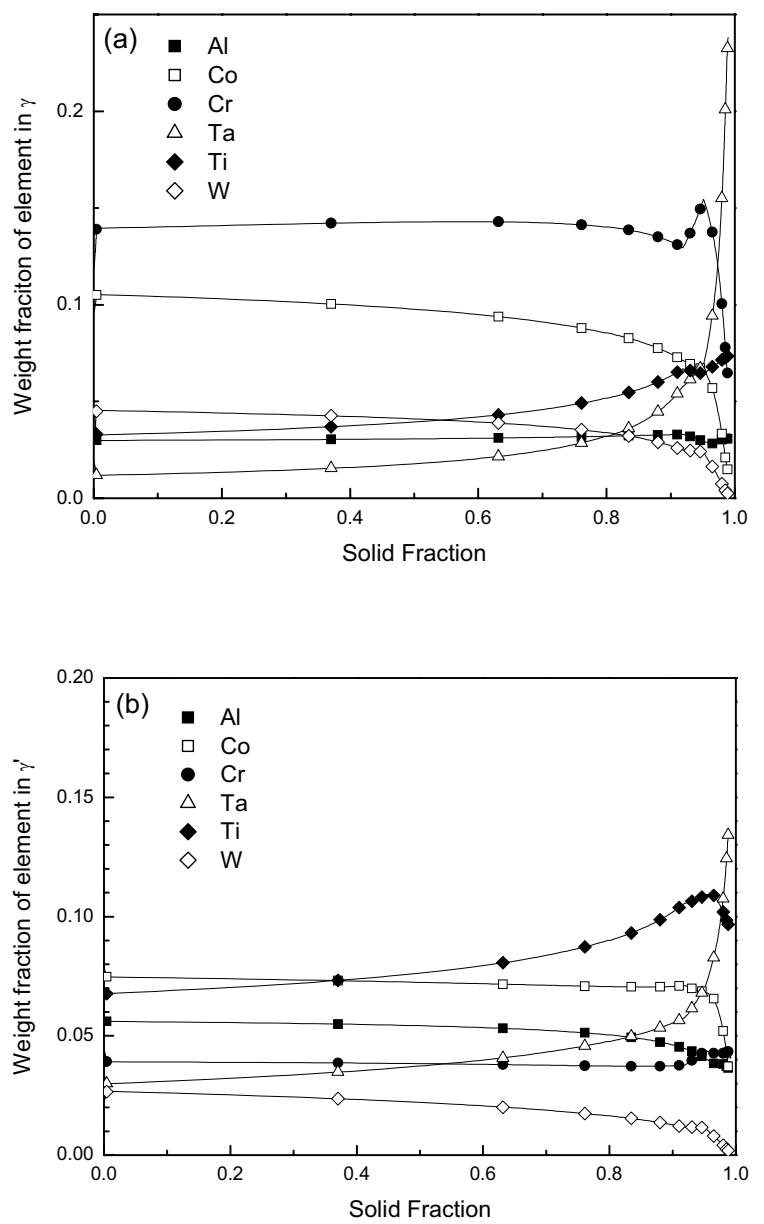

Fig. 4. Calculated segregation after solidification of GTD-111 in (a) the gamma phase and (b) the gamma prime.

Small particles of high density tend to coarsen into larger particles of lower density to reduce total interfacial energy. Assuming volume diffusion is the rate control factor, $\gamma^{\prime}$ coarsening during thermal exposure can be given as the following equation ${ }^{12}$,

$$
\begin{aligned}
& \bar{d}^{3}-\bar{d}_{o}^{3}=K t \\
& K=\frac{64 C_{e} \gamma_{s} D V_{m}^{2}}{9 R T}
\end{aligned}
$$

where $d$ is the average $\gamma^{\prime}$ diameter, $d_{o}$ is the initial average $\gamma^{\prime}$ diameter at time $0, t$ is time, $C_{e}$ is the equilibrium concentration of $\gamma^{\prime}$ solute in $\gamma, \gamma_{\mathrm{s}}$ is the interfacial free energy, $R$ is the gas constant, 
$T$ is the temperature, $D$ is the diffusion coefficient of $\gamma^{\prime}$ solutes in $\gamma, V_{m}$ is the molar volume of $\gamma^{\prime}$. Considering the diffusion coefficient, $D$ in equation (1) can be given as $D=D_{o} \exp (-Q / R T)$ where $Q$ is the activation energy for diffusion, $Q$ can be calculated from the plot of $\ln K T$ versus $1 / T$ as shown in Figure 6.

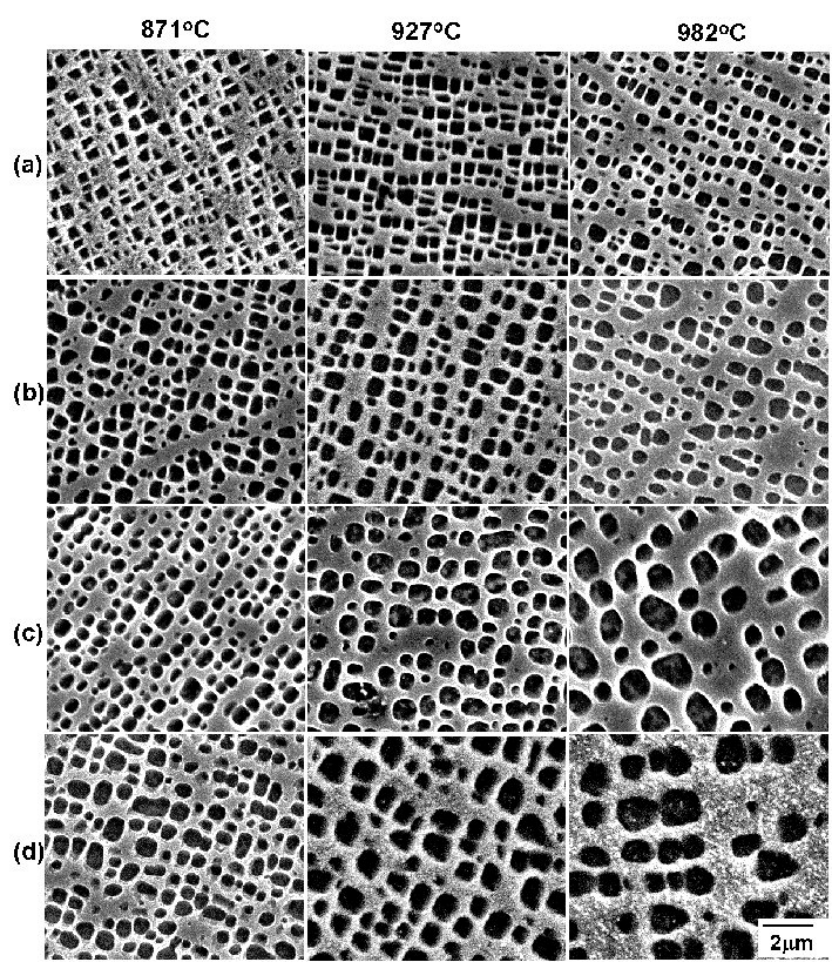

Fig. 5. Variation of $\gamma^{\prime}$ size and distribution during thermal exposure. (a) 50hours, (b) 800hours, (c) 5000 hours, (d) 10000 hours.

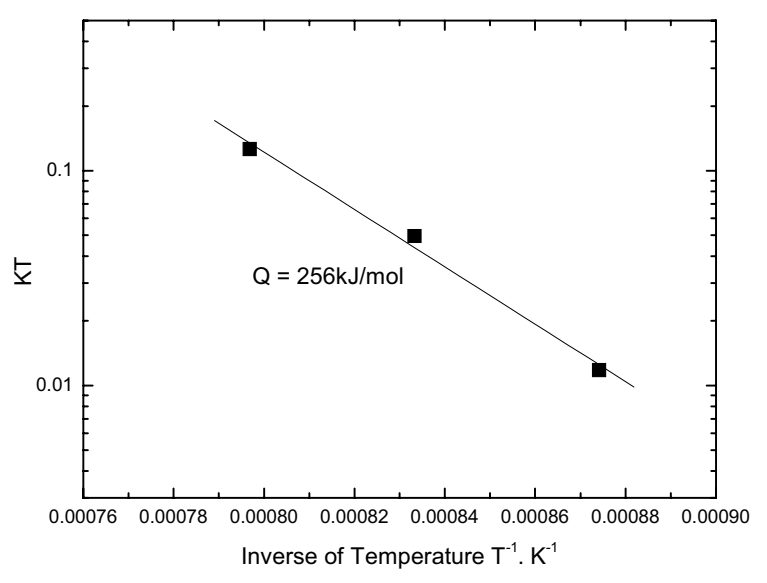

Fig. 6. Determination of activation energy for $\gamma^{\prime}$ coarsening using temperature dependence of rate constant $\mathrm{K}$.

Activation energy for $\gamma^{\prime}$ coarsening was calculated as $256 \mathrm{~kJ} / \mathrm{mol}$ in this study, which is similar to the activation energy calculated in the other report, $259 \mathrm{~kJ} / \mathrm{mol}^{1}$. This result implies the coarsening of $\gamma^{\prime}$ is controlled by the diffusion of $\gamma^{\prime}$ forming elements such as $\mathrm{Ti}$ or $\mathrm{Al}$, because the value of activation energy is similar to that of diffusion for $\mathrm{Ti}$ or $\mathrm{Al}$ in $\mathrm{Ni}$.

\section{Eta Formation during Thermal Exposure on Grain Boundary}

Two different types of carbide, $\mathrm{MC}$ and $\mathrm{M}_{23} \mathrm{C}_{6}$, were observed on the grain boundary of the standard heat treated alloy. It is known that the MC carbide had a tendency to decompose with thermal exposure into $\mathrm{M}_{23} \mathrm{C}_{6}$ and $\gamma^{\prime}$ film ${ }^{13}$. In this case, growth of $\mathrm{M}_{23} \mathrm{C}_{6}$ carbide on grain boundary makes the alloy locally enriched with

(a)
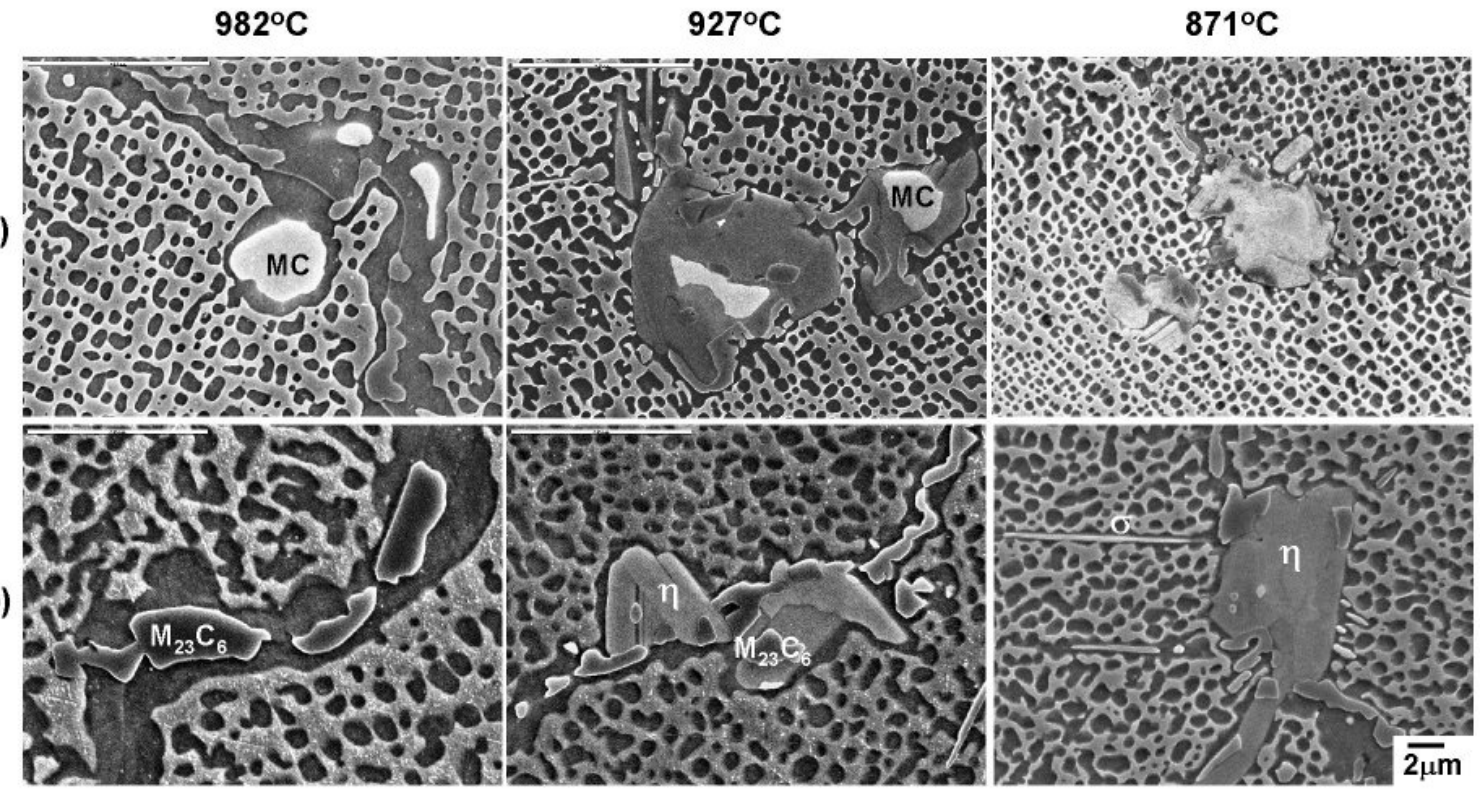

Fig. 7. Evolution of grain boundary structure during thermal exposure. (a) 2000 hours and (b) 10000 hours. Bright blocky phase is MC, bright acicular phase is $\sigma$, dark blocky phase is $\mathrm{M}_{23} \mathrm{C}_{6}$, and gray plate and blocky phase is $\eta$ phase. 
$\gamma$ ' forming elements, $\mathrm{Al}$ and $\mathrm{Ti}$, allowing the film of $\gamma^{\prime}$ to form along the grain boundary.

The decomposition of MC in GTD 111 showed different behaviors at different exposure temperatures. After thermal exposure at $982^{\circ} \mathrm{C}$, the grain boundary of GTD 111 was covered with discontinuous $\mathrm{M}_{23} \mathrm{C}_{6}$ carbides enveloped by $\gamma^{\prime}$ film as shown in Figure 7. However, platelet and/or blocky phase formed near MC after exposure at $927^{\circ} \mathrm{C}$ and $871^{\circ} \mathrm{C}$ instead of $\gamma^{\prime}$ film. From the SADP of the phase, Figure 8 (a), the phase was identified as $\eta$ phase. While $\eta$ phase looked like platelet phase at the initial stage of formation, it developed into blocky type as exposure time increased. $\mathrm{M}_{23} \mathrm{C}_{6}$ with high $\mathrm{Cr}$ content formed within $\eta$ phase was also found. Therefore, the degeneration of $\mathrm{MC}$ carbide at and below $927^{\circ} \mathrm{C}$ could given as;

$\gamma+\mathrm{MC} \rightarrow \eta+\mathrm{M}_{23} \mathrm{C}_{6}$

Figure 9 is the phase diagram calculated by THERMOCALC to show the equilibrium phases at each temperature as a function of $\mathrm{Ti}$ weight fraction. The dashed line indicates the $\mathrm{Ti}$ content of GTD 111. While the $\eta$ phase cannot be expected to form with this composition as shown in the diagram increasing $\mathrm{Ti}$ contents enables formation of $\eta$ phase. It is known that the $\gamma^{\prime}$ containing sufficiently high aluminum is stable but another type of $\mathrm{Ni}_{3} \mathrm{X}$ compounds can be more stable when high amounts of $\mathrm{Al}$ in $\mathrm{Ni}_{3} \mathrm{Al}$ is replaced by $\mathrm{Ti}, \mathrm{Nb}$ or $\mathrm{Ta}^{13}$. Considering segregation behavior discussed previously, Ti and Ta contents on grain boundary could be higher than nominal composition. In addition, during decomposition of $\mathrm{MC}$, Ta and $\mathrm{Ti}$ separated from $\mathrm{MC}$ then the elements were enriched at grain boundary. High amounts of Ti and Ta made $\gamma^{\prime}$ to be unstable and $\eta\left(\mathrm{Ni}_{3} \mathrm{Ti}\right)$ phase formed during degeneration of MC carbide instead of $\gamma^{\prime}$. At these temperatures, $\mathrm{M}_{23} \mathrm{C}_{6}$ enveloped by $\gamma^{\prime}$ film was also found especially on the grain boundary apart from MC carbides. Some of carbon atoms ejected during $\mathrm{MC}$ carbide decomposition can diffuse along grain boundary to coarsen $\mathrm{M}_{23} \mathrm{C}_{6}$ and others form new $\mathrm{M}_{23} \mathrm{C}_{6}$ carbide near $\eta$ phase. However, $\eta$ phase forms only near $\mathrm{MC}$ carbide which is the source of the $\eta$ forming elements, Ti and Ta during thermal exposure. This result implies that the $\eta$ formation has to be accompanied by $\mathrm{MC}$ decomposition which releases $\mathrm{Ti}$ and $\mathrm{Ta}$ atoms.

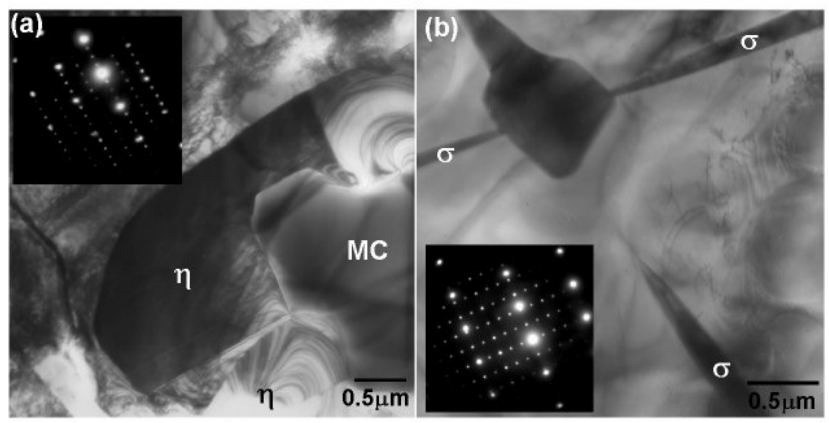

Fig 8. Identification of phases using SADP, (a) $\eta$ on grain boundary after thermal exposure at $927^{\circ} \mathrm{C}$ for 2000 hours, (b) $\sigma$ after thermal exposure at $8710 \mathrm{C}$ for 10000 hours.

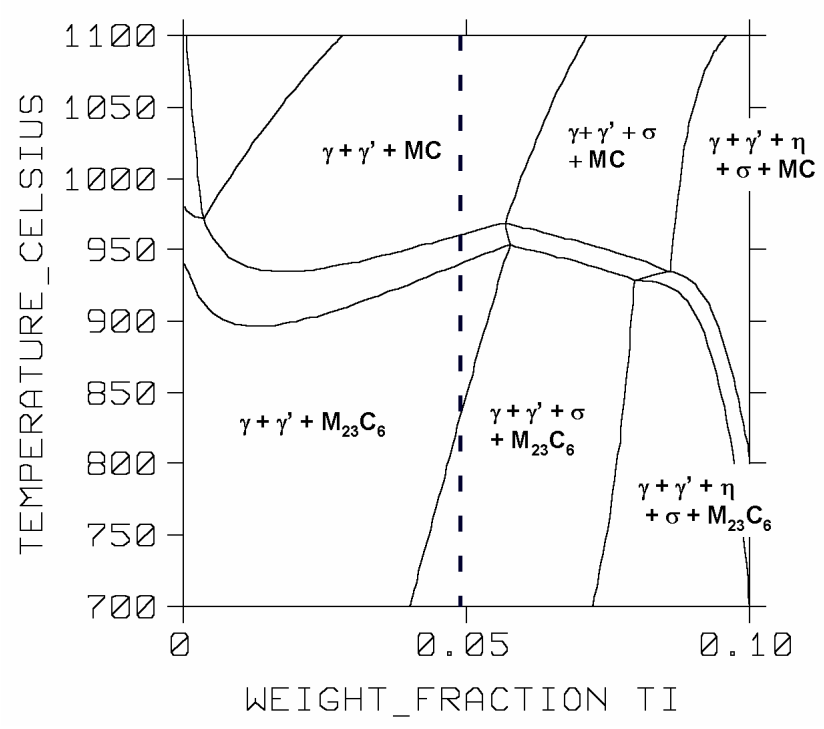

Figure 9. Phase diagram of GTD-111 as a function of Ti weight fraction. Segregation is not considered and dashed line indicates the Ti content of the GTD 111.

Acicular phase was also found near grain boundary of the specimen exposed at $871^{\circ} \mathrm{C}$ and $927^{\circ} \mathrm{C}$. From the SADP in Figure 8 (b), the acicular phase can be identified as $\sigma$ phase which has high contents of $\mathrm{Cr}$ and $\mathrm{Ni}^{14}$. Relatively high amount of $\sigma$ was found in the specimen exposed at $871 \mathrm{oC}$ than that exposed at $927^{\circ} \mathrm{C}$.

\section{Eutectic Gamma-Gamma Prime $\left(\gamma-\gamma^{\prime}\right)$}

The microstructural evolution in eutectic region was similar to that on grain boundary as shown in Figure 10. MC carbides decomposed into $\mathrm{M}_{23} \mathrm{C}_{6}$ and $\gamma^{\prime}$ at $982^{\circ} \mathrm{C}$ but $\eta$ phase formed with $\mathrm{M}_{23} \mathrm{C}_{6}$ at $871^{\circ} \mathrm{C}$ and $927^{\circ} \mathrm{C}$. Acicular $\sigma$ phase was also found in the alloy exposed at $871^{\circ} \mathrm{C}$ and $927^{\circ} \mathrm{C}$. However, variation was slower in the eutectic region than on the grain boundary, even though this area has much higher contents of $\eta$ forming elements such as Ta and Ti due to segregation. The slower evolution rate of microstructure in eutectic region may be attributed to lower diffusivity of solute atoms. Fine platelet $\eta$ phase existed after standard heat treatment disappeared during thermal exposure at $982^{\circ} \mathrm{C}$. It was reported that the most of coarse platelets formed during casting process were not dissolved during solution treatment ${ }^{8}$. Fine platelets formed during heat treatment, however, can be dissolved during thermal exposure.

\section{EFFECT OF ETA PHASE ON MECHANICAL PROPERTIES}

\section{$\underline{\text { Tensile Properties }}$}

Tensile properties of standard heat treated specimen and thermally exposed specimens at $927^{\circ} \mathrm{C}$ ad $982^{\circ} \mathrm{C}$ are shown in Figure 11. Tensile strengths of thermally exposed specimens (designate 'exposed specimens' hereafter) were lower than that of standard 


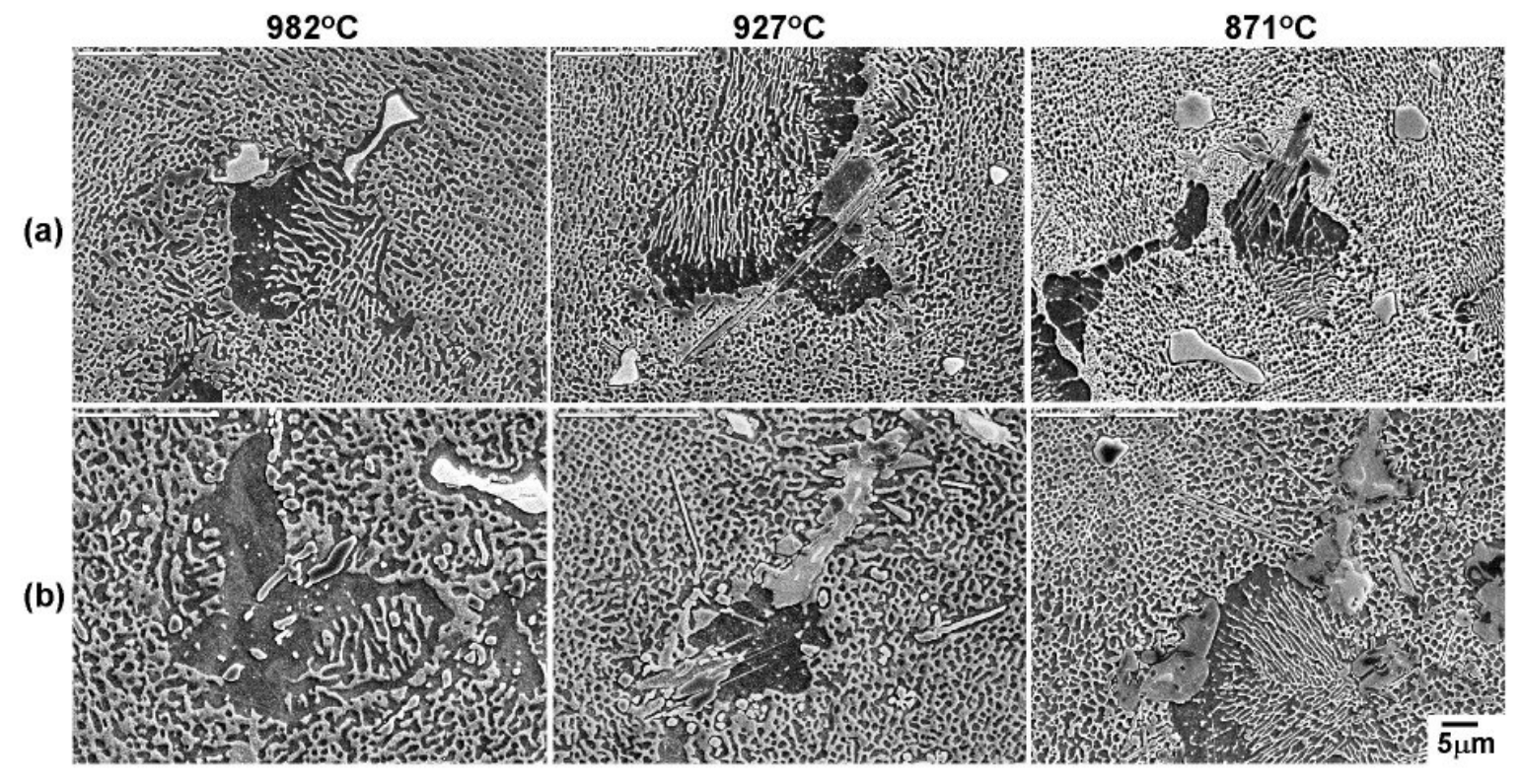

Fig. 10. Evolution of eutectic during thermal exposure for (a) 2000 hours and (b) 10000 hours.

heat treated specimen at both room temperature and $650^{\circ} \mathrm{C}$. The strengths decrease slightly with increasing of exposure time.

The major contribution to the strength of precipitation-hardened nickel base superalloys is provided by intermetallic compound, $\gamma^{\prime 13}$. Moving dislocations can pass gamma prime particles by cutting or Orowan bypass mechanism. The coarsening of fine gamma prime can lead to change of the mechanism from particle cutting to Orowan bowing ${ }^{13}$. Dislocations probably pass the fine secondary particles by cutting mechanism and pass the large primary particles by Orowan bowing. This assumption is adaptable because the critical size to change the dislocation passing mechanism from cutting to Orowan bowing was calculated as $0.05 \mu \mathrm{m}$ in case of IN738LC at $850^{\circ} \mathrm{C}^{14}$. Therefore, dissolving of secondary $\gamma^{\prime}$ during thermal exposure leads to the reduction of strengths of exposed specimen.

The threshold stress to overcome the particle decreases as the particle size increases when Orowan bowing is the dominant mechanism. However, the decrease of stress becomes insignificant as particle size increased. This will be proper explanation for slight change of strength with increasing of exposure time.

The specimens exposed at $927^{\circ} \mathrm{C}$ show lower ductility at room temperature than those exposed at $982^{\circ} \mathrm{C}$. Fracture surfaces after tensile tests were observed by SEM as shown in Figure 12. Dendrite structure was observed on the fracture surface, which indicates interdendritic failure. Figure 12 (b) and (e) display the fracture surface with higher magnification. Some regions with dimpled surface, one of the characteristics of ductile fracture, can be found in fracture surface of the specimen exposed at $982^{\circ} \mathrm{C}$. Some cracked $\eta$ phases along grain boundary were also observed in the longitudinal section of the specimens exposed at $927^{\circ} \mathrm{C}$ after tensile test as shown in Figure 12 (f). Considering the difference in fracture surface and cracks on $\eta$ phase, lower ductility of specimen aged at $927^{\circ} \mathrm{C}$ is attributed to the existence of $\eta$ phase which has brittle feature with little strain tolerance. While the room temperature ductility is affected by $\eta$ phase, both the strengths and the elongation of exposed specimens are not significantly affected by exposure conditions at $650^{\circ} \mathrm{C}$, as shown in Figure 11.

The results of tensile tests are summarized that the $\eta$ phase formed along grain boundary during thermal exposure reduces the ductility by a little at room temperature, however do not have deleterious effect on strength and high temperature ductility

\section{$\underline{\text { Creep Tests }}$}

The specimens were aged at four different exposure conditions to investigate the effects of grain boundary $\eta$ phase and coarsening of $\gamma^{\prime}$ on creep properties. The $\gamma^{\prime}$ size distributions of the specimens exposed at $982^{\circ} \mathrm{C}$ for 1000 hours and 2000 hours, $927^{\circ} \mathrm{C}$ for 2000 hours, and $871^{\circ} \mathrm{C}$ for 10000 hours are shown in Figure 13. The alloy exposed at $982^{\circ} \mathrm{C}$ for 1000 hours has similar $\gamma^{\prime}$ size distribution to that exposed at $927^{\circ} \mathrm{C}$ for 2000 hours which have $\eta$ phase on their grain boundary and that exposed at $871^{\circ} \mathrm{C}$ for 10000 hours which have $\eta$ phase and higher amount of $\sigma$ phase interior of the grain. The alloy exposed at $982^{\circ} \mathrm{C}$ for 2000 hours has larger $\gamma^{\prime}$ than that exposed for 1000 hours at the same temperature, but both specimens have similar grain boundary structure.

Creep test were conducted at four different test conditions, $927^{\circ} \mathrm{C}$ $/ 210 \mathrm{MPa}, 871^{\circ} \mathrm{C} / 320 \mathrm{MPa}, 816^{\circ} \mathrm{C} / 440 \mathrm{MPa}$ and $760^{\circ} \mathrm{C} / 550 \mathrm{MPa}$. Figure 14 show creep rupture lives as a Larson-Miller plot. Exposed specimens showed relatively short creep rupture lives except the test at $927^{\circ} \mathrm{C} / 210 \mathrm{MPa}$. As the test temperature decreased, the deterioration of the creep property due to thermal 
exposure appeared to be evident. Regardless of exposed condition, creep rupture lives of exposed specimens were similar.

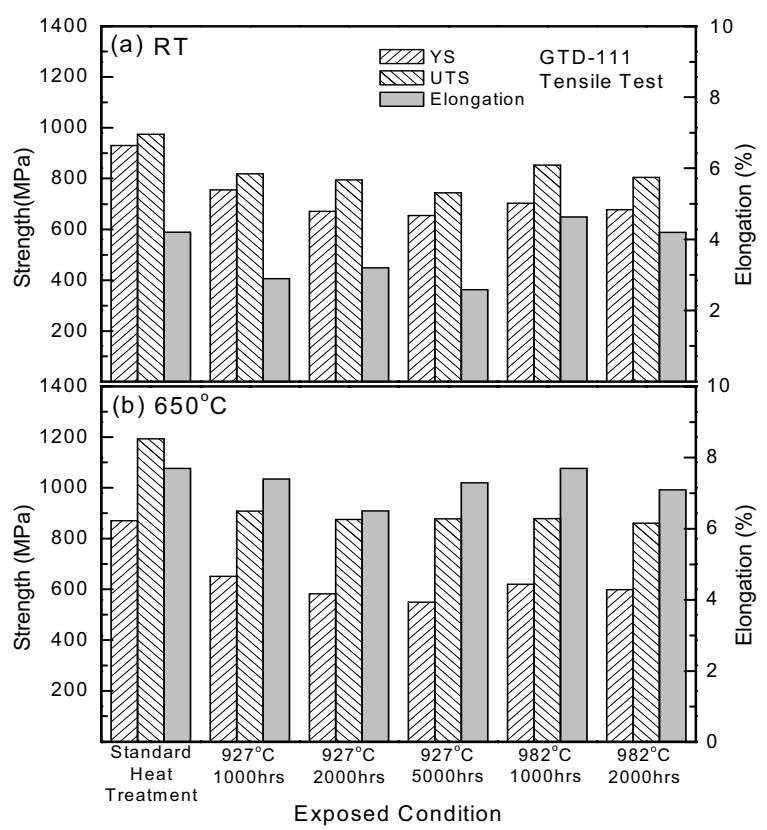

Fig. 11. Results of tensile tests at room temperature and $650 \mathrm{oC}$.
The creep curves at $816^{\circ} \mathrm{C} / 440 \mathrm{MPa}$ are shown in Figure 15 Exposed specimens show higher creep rate than standard heat treated one. The creep curves of specimens exposed at $927^{\circ} \mathrm{C}$ and $982^{\circ} \mathrm{C}$ are similar. Considering the grain boundary structure and $\gamma^{\prime}$ distribution of these specimens, the effects of grain boundary $\eta$ phase and the small variation of primary $\gamma^{\prime}$ size on creep properties seems to be negligible.

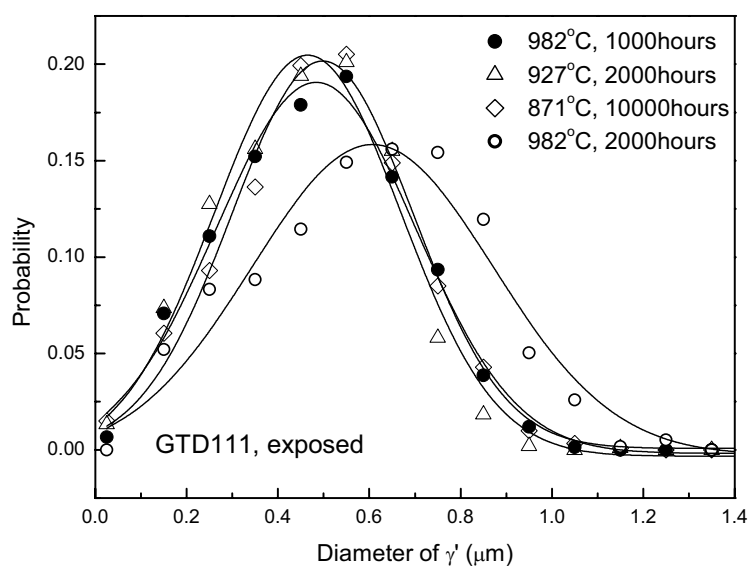

Fig. 13. Distribution of gamma prime size at four different exposure conditions.
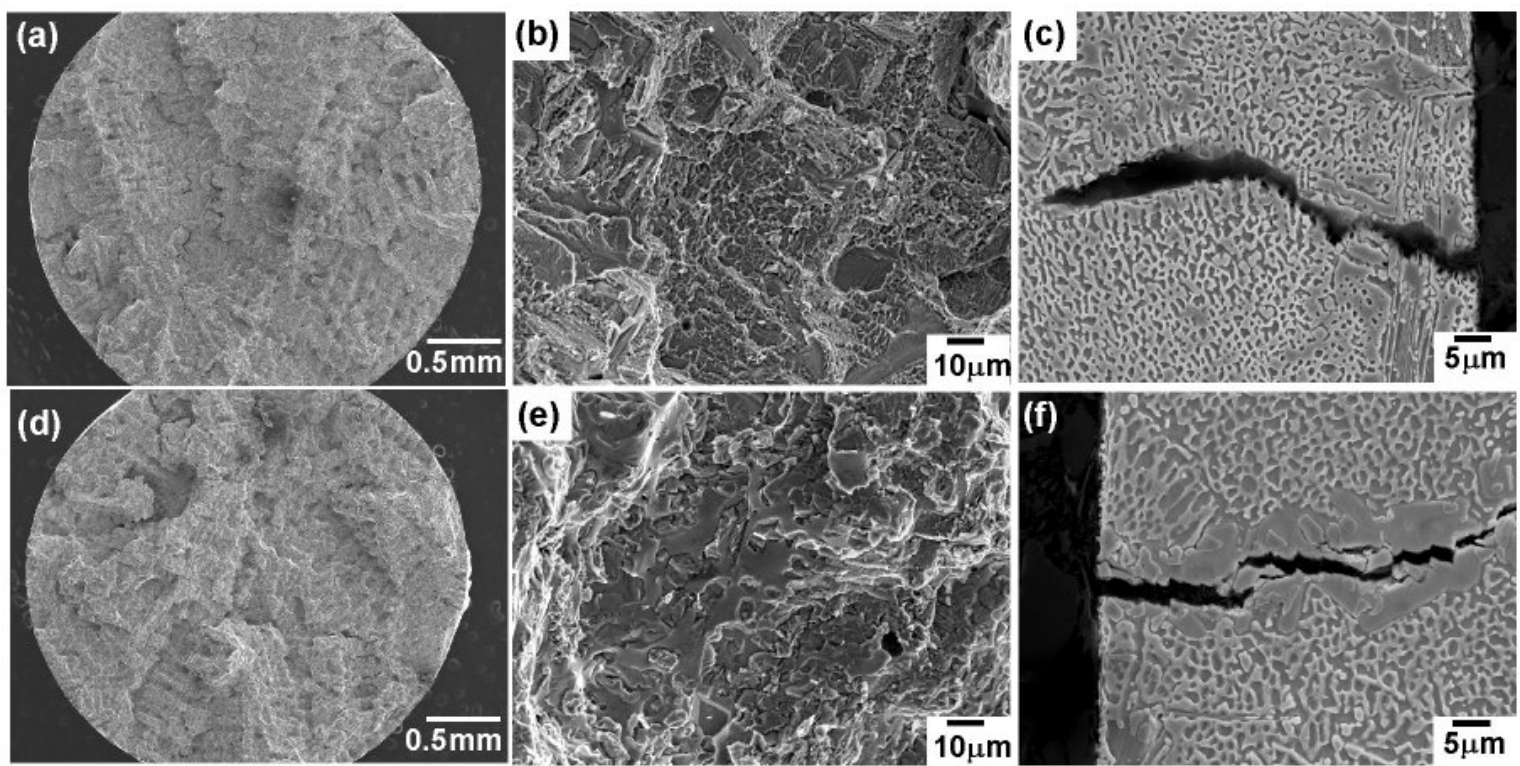

Figure 12. SEM micrographs showing fracture surface and longitudinal section after room temperature tensile tests.

(a) and (d) fracture surface, (b) and (e) fracture surface with high magnification, and (c) and (f) longitudinal section showing secondary cracks exposed at $982^{\circ} \mathrm{C}$ for 2000 hours and $927^{\circ} \mathrm{C}$ for 5000 hours, respectively. 


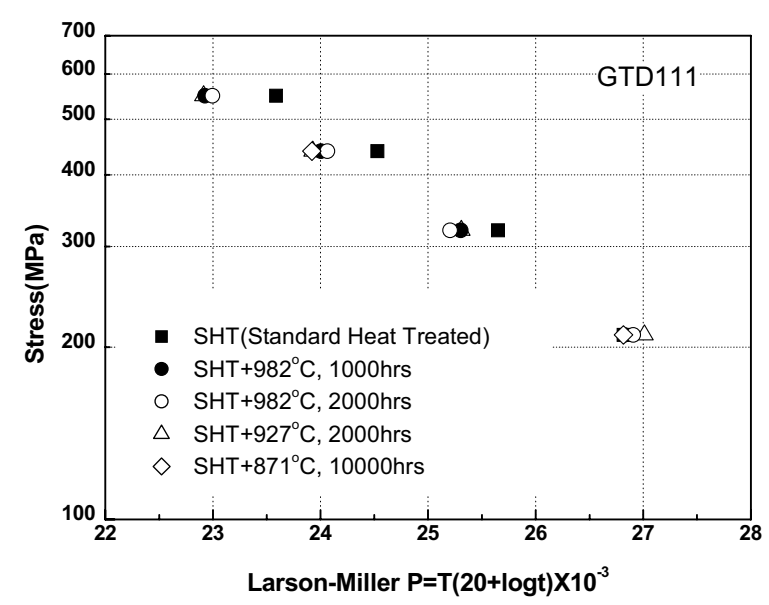

Fig. 14. Larson-Miller plot of GTD 111.

The specimen exposed at $871^{\circ} \mathrm{C}$ for 10000 hours shows faster creep deformation than other specimens. This specimen has more amount of sigma phase than other specimens and smaller $\gamma^{\prime}$ than the specimen exposed at $982^{\circ} \mathrm{C}$ for 2000 hours. It is well known that the TCP phase like $\sigma$ has deleterious effects on mechanical properties in two different ways ${ }^{15}$. The phase can act as barrier for moving dislocations leading to interfacial decohesion and crack initiation. TCP phase formation consumes the solid solution strengthening elements of the alloy. The depletion of strengthening elements results in the softening of the $\gamma$ matrix. Microstructural observation on longitudinal sections of ruptured specimen revealed the effect of the $\sigma$ phase on creep rupture. As shown in Figure 16, near main crack propagated along grain boundary, small cracking across the $\sigma$ was observed. However, the cracks did not propagate into $\gamma$ matrix. The creep ductility of this condition was not lower than other conditions as shown in Figure 15 (a). Therefore, $\sigma$ in matrix did not have significant effect on creep fracture behavior of the exposed specimen.

Softening of $\gamma$ phase due to depletion of strengthening elements may accelerate the creep deformation. However, The reason of higher creep rate of the specimen exposed at $871^{\circ} \mathrm{C}$ for 10000 hours is seems to be related with not only the compositional change due to precipitation of $\sigma$ but also the variation of composition and properties of $\gamma$ and $\gamma^{\prime}$ with different exposure temperatures because the interaction between dislocations and $\gamma^{\prime}$ depends on several factors; size and volume fraction of $\gamma^{\prime}$, antiphase boundary energy of $\gamma^{\prime}$ and interfacial conditions such as misfit between $\gamma$ and $\gamma^{\prime}$.

Under high temperature and low stress conditions $\left(927^{\circ} \mathrm{C} /\right.$ $210 \mathrm{MPa}$ ), no remarkable deleterious effects of thermal exposure on creep rupture lives and creep deformation behaviors are found as shown in Figure 14 and Figure 15. It is known that the fine secondary $\gamma^{\prime}$ plays an important role on creep behavior compared with primary $\gamma^{\prime}$ size $^{16}$. Standard heat treated specimen had both primary $\gamma^{\prime}$ and secondary fine $\gamma^{\prime}$, but secondary $\gamma^{\prime}$ dissolved during thermal exposure. Because at high temperature such as $927^{\circ} \mathrm{C}$ secondary $\gamma^{\prime}$ in standard heat treated specimen was dissolved fast during creep test, its effect on creep property was also diminished at the early stage of creep ${ }^{1}$. Therefore, the creep property was not dependent on exposure condition at $927^{\circ} \mathrm{C}$ because the effect of primary $\gamma^{\prime}$ size on creep strength was not significant in the present study.
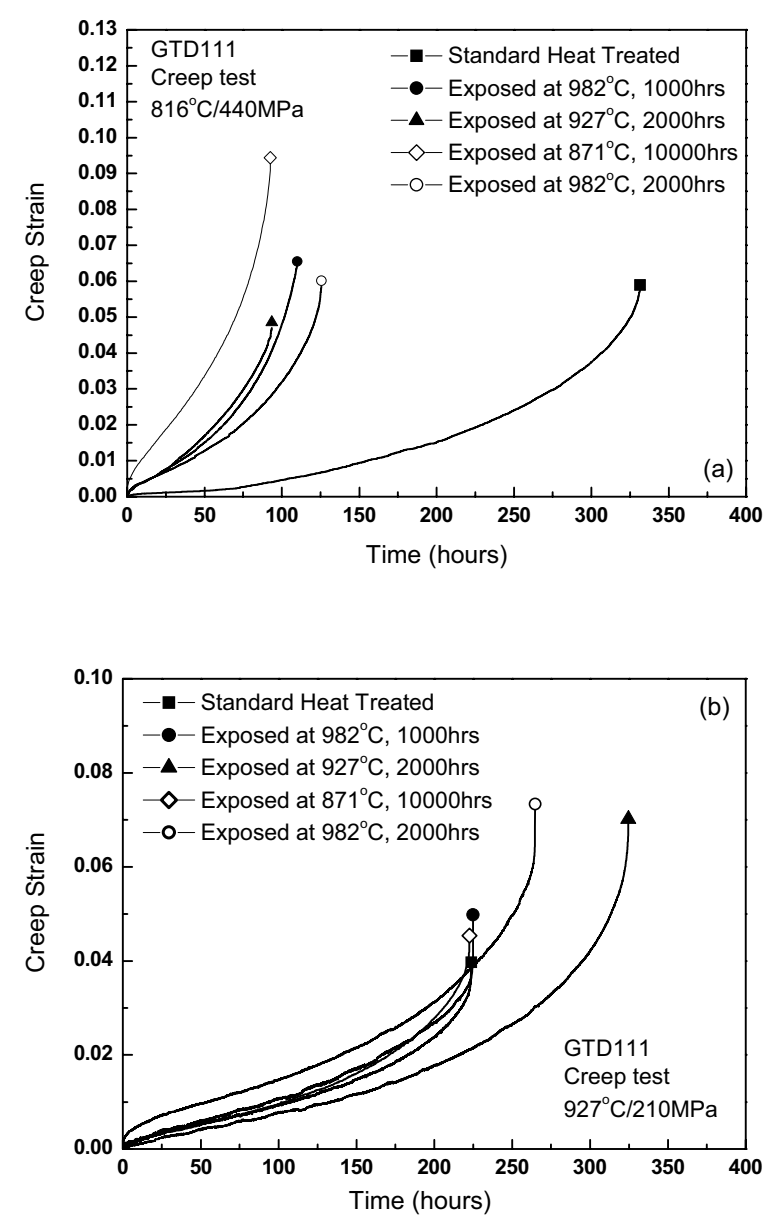

Figure 15. Creep curves at (a) $816^{\circ} \mathrm{C} / 440 \mathrm{MPa}$, (b) $927^{\circ} \mathrm{C} / 210 \mathrm{Mpa}$

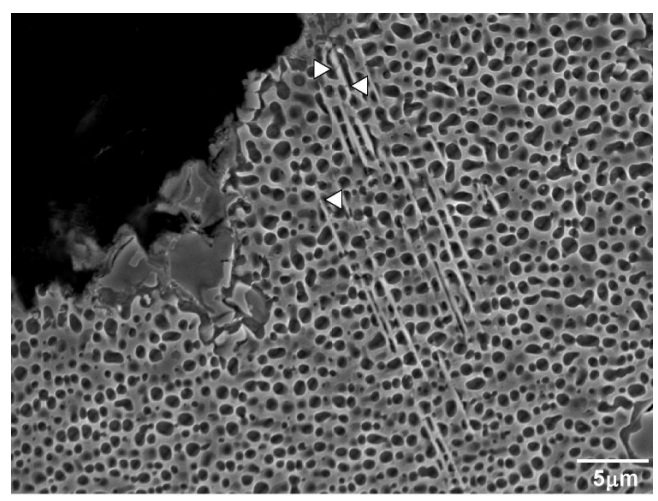

Figure 16. SEM micrograph showing longitudinal section of exposed specimen exposed at $871^{\circ} \mathrm{C}$ for 10000 hours after creep at $816^{\circ} \mathrm{C} / 440 \mathrm{MPa}$ (arrows indicate small cracks on $\sigma$ phase) 


\section{CONCLUSIONS}

1. Platelet $\eta$ phase was found near $\gamma-\gamma^{\prime}$ eutectic in as-cast, solutionized, and standard heat treated GTD 111. Segregation caused formation of fine platelet $\eta$ phase during solutionizing. 2. MC carbide on grain boundary degenerated during exposure in various ways with the exposure temperature. They decomposed into $\mathrm{M}_{23} \mathrm{C}_{6}$ and $\gamma^{\prime}$ film at $982^{\circ} \mathrm{C}$ but into $\eta$ and $\mathrm{M}_{23} \mathrm{C}_{6}$ at and below $927^{\circ} \mathrm{C}$. $\sigma$ was found most abundantly in the alloy exposed at $871^{\circ} \mathrm{C}$.

3. Grain boundary $\eta$ phase reduces the ductility a little at room temperature, however do not have deleterious effect on strength and high temperature.

4. $\eta$ phase and small change of primary $\gamma^{\prime}$ size affect neither rupture life nor creep ductility.

\section{REFERENCES}

1. J. A. Daleo and J. R. Wilson, 'GTD 111 Alloy Material Study', Journal of Engineering of Gas Turbines and Power, 1998, 120 (4), 375-382

2. H. E. Collins, 'The Effect of Thermal Exposure on the Microstructure and Mechanical Properties of Nickel-Base Superalloys', Metall. Trans., 1974, 5 (1) 189-204

3. M. Nazmy and M. Staubli, 'Embrittlement of Several NickelBase Alloys after High-Temperature Exposure', Scripta Metall. Mater., 1990, 24, 135-138

4. H. E. Collins, 'The Effect of Thermal Exposure on the Mechanical Properties of the Directionally Solidified Superalloy TRW-NASA VIA', Metall. Trans., 1975, 6A (3), 515-530.

5. S.A. Sajjadi and S. Natech, 'A High Temperature Deformation Mechanism Map for the high Performance Ni-base Superalloy GTD-111', Mater. Sci. Eng., 2001, A307, 158-164.

6. S.A. Sajjadi, S. Natech, and R. I. L. Guthrie, 'Study of microstructure and Mechanical Properties of High Performance Ni-base Superalloy GTD-111', Mater. Sci, Eng., 2002, A325, 484-489.

7. S. Natech and S.A. Sajjadi, 'Dislocation Network Formation during Creep in Ni-base Superalloy GTD-111', Mater. Sci, Eng., 2003, A339, 103-108.

8. G. K. Bouse, 'Eta and Platelet Phases in Investment Cast Superalloys', Superalloys 1996, R. D. Kissinger et. al. ed., A Publication of TMS, 1996, 163-172

9. B. S. Rho and S. W. Nam, 'Fatigue induced precipitates at grain boundary of Nb-A286 Alloy in High Temperature Low Cycle Fatigue', Mater. Sci. Eng, 2000, A291, 54-59.

10. N. Saunders, M. Fahrmann, and C. J. Small, 'The Application of CALPHAD calculations to Ni-based superalloy', Superalloys 2000, T. M. Pollock et. al. ed., A Publication of TMS, 2000, 803811

11. M. J. Starink and R. C. Thomson, 'The Effect of High Temperature Exposure on Dendritic Segregation in a Conventionally Cast Ni Based Superalloy', J. Mater. Sci., 2001, 36, 5603-5608

12. D. J. Chellman and A. J. Ardell, 'The Coarsening of $\gamma$ ' Precipitates at Large Volume Fractions', Acta Met. 1974, 22, 577 588

13. E. W. Ross and C. T. SIMS, superalloy II, C. T. SIMS et. al. ed., John Wiley \& Sons, 1987, 97-134
14. B. G. Choi, D. W. Joo, I. S. Kim, J. C. Chang and C. Y. Jo, 'Effect of Thermal Exposure and Rejuvenation Treatment on Microstructure and Stress Rupture Properties of IN738LC', Korean Journal of Materials Research, 2001, 11(10) 915-922.

15. M. Simonetti and P. Caron, 'Role and behaviour of $\mu$ phase during deformation of a nickel-based single crystal superalloy', Mater. Sci. Eng., 1998, A254, 1-12

16. K. Kakehi, 'Effect of Primary and Secondary Precipitates on Creep Strength of Ni-Base Superalloy Single Crystal', Mater. Sci. Eng., 2000, A278, 135-141 
